\title{
As manifestações e a questão da reforma urbana: é possível retomar a capacidade de planejamento e intervenção?
}

\author{
Angela Welters* \\ Demian Castro** \\ Igor Zanoni Constant Carneiro Leão***
}

Resumo: $\mathrm{O}$ artigo discute, a propósito das manifestações de junho de 2013, a necessidade de incluir e articular analiticamente três eixos de problemas que obstruem a capacidade de planejamento dos governos municipais, pois tendem a produzir uma privatização perversa do habitat urbano, afetando o modo de vida das pessoas e, também, à sua mobilidade. Estes eixos, quais sejam, a industria automobilística, o capital imobiliário e a (in) segurança urbana, por sua vez, suscitam outras questões que são tratadas na forma de réplica.

Palavras-chave: Demandas Sociais, Planejamento, Cidades

Classificação JEL: O18.

\footnotetext{
* Economista, professora do departamento de economia da UFPR. E-mail: angela.welters@gmail.com ** Economista, professor do departamento de economia da UFPR. E-mail: demian@ufpr.br

*** Economista, professor do departamento de economia da UFPR. E-mail: igorzaleao@yahoo.com.br
} 


\section{Introdução}

Num país com mazelas sociais históricas como o Brasil, as manifestações de junho de 2013 parecem acenar com uma mudança em relação ao relativo conformismo da população até então. Isto se deve, em grande medida, ao fato de que as grandes cidades brasileiras apresentam-se cada vez mais como um espaço conflituoso e ineficiente em funções primordiais: mobilidade urbana, convivência cidadã, segurança e habitação digna. Emerge daí certo consenso de que o espaço urbano precisa ser repensado. As reflexões que se seguem pretendem contribuir modestamente para esta tarefa complexa e ao mesmo tempo urgente. Cientes do caráter preliminar e provocativo das questões, os autores optaram por apresentar um texto aberto, contendo uma primeira parte mais propositiva, uma segunda parte, na forma de uma réplica e, uma conclusão entendida mais como síntese de possíveis encaminhamentos temáticos do que como fechamento de temas ou assuntos.

\section{Automóveis, capital imobiliário e segurança: contribuindo para a privatização das cidades.}

A sociedade brasileira decidiu sair da zona de conforto. Em junho deste ano, durante a copa das confederações, milhares de jovens invadiram as ruas em manifestações inesperadas, focadas no transporte público, principalmente, mas coexistindo com outras demandas, por exemplo, no campo da saúde e da educação. No fundo, a grande questão, para além de demandas variadas, envolve a construção da cidadania e a natureza dos espaços urbanos que habitamos.

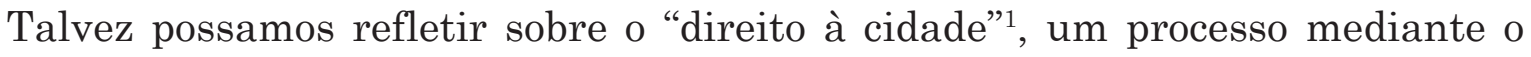
qual a construção individual, a trajetória de cada um é, simultaneamente, a construção da cidade, uma utopia capaz de abrigar e possibilitar os sonhos de cada um. Todos os recantos do Brasil foram, de certa maneira, acordados por manifestações. O mote do movimento, as tarifas do transporte público, assemelha-se a um cavalo de tróia, que abriga desde um basta à corrupção até saúde e educação pública de qualidade. Os manifestantes explicitaram que o longo e tortuoso caminho democrático rende seus frutos: não se aceita mais o futebol como droga alienadora, como válvula de escape à tensão gerada por uma questão social e urbana geradora de conflitos e infelicidade. Ao mesmo tempo, as manifestações questionaram a representação partidária e o congresso; a "casa do povo" transformou-se em "casa dos lobbies e das corporações", de uma classe política profissional autonomizada e descolada da sociedade. O que ocorreu em junho vem arejar nossa visão de cidadania e aponta para um conceito dinâmico que permanentemente será testado e validado por novas condições sociais e novos enfoques sobre os direitos e o bem estar dos indivíduos.

O movimento pode ter tido algum caráter ciclo tímico, ligado à ocorrência de grandes eventos e por isto seu arrefecimento mais recente. No entanto, Ver Harvey (2013): “A questão do tipo de cidade que desejamos é inseparável da questão do tipo de pessoa que
desejamos nos tornar. A liberdade de fazer e refazer a nós mesmos e a nossas cidades dessa maneira é sustento, um dos mais preciosos de todos os direitos humanos". (pág.28) 
como sintoma de uma doença grave, o que tem ocorrido indica o esgotamento da paciência ou da capacidade de acomodação da sociedade (o que certamente extrapola a questão das tarifas do transporte público) porque, definitivamente, os espaços urbanos brasileiros, de qualquer tamanho que sejam, não permitem construir um estado de bem estar nem paz social. Observe-se que a dicotomia "manifestação pacífica" ou vandalismo, o tempo todo presente, expressa os contornos frágeis de uma situação social explosiva, junto à sociedade que se mobiliza democraticamente, há bandidos, narco traficantes, blacks blocks, punks e anarquistas. Não adianta moralizar o que é produto de uma cidade que obstrui sistematicamente a felicidade coletiva e a paz social. Não adianta proibir rostos encobertos quando sistematicamente os aparelhos mediáticos e os governos turvam a visão da realidade.

No final dos anos setenta, durante a luta contra a ditadura, os movimentos sociais brasileiros defenderam a necessidade de uma reforma urbana, realizada de "baixo para cima", com ampla participação popular. Entendia-se que, em conseqüência da violenta urbanização, as cidades tinham crescido, não apenas de modo desordenado, mas, principalmente, de modo excludente: qualquer que fosse o núcleo urbano, seu lado moderno crescia formando periferias e segregando, levando os mais pobres sempre mais longe dos centros. Tal qual a reforma agrária, nas cidades, a democratização não produziu qualquer reforma relevante, em parte, pela crise fiscal e financeira do Estado. $\mathrm{O}$ tema foi abandonado e as cidades, qual a "E la Nave vá" de Fellini, cresceram de qualquer forma e os governos foram, a passos largos, ficando no córner, sem capacidade política e financeira de realizar grandes intervenções e de regular as forças motrizes de seu inevitável crescimento ${ }^{2}$. Apesar dos avanços legais obtidos com a Constituição de 1988, o Ministério das Cidades (2003), do Estatuto da Cidade (2001) e, mais recentemente, do projeto de lei 3460 de 2004, que cria o Estatuto da Metrópole (tramitando na Câmara dos Deputados), a falta crônica de crescimento e a corrupção conjugaram para comportamentos frouxos ou lenientes relativos ao espaço público e o lugar das decisões privadas. Mais ainda, decisões, absolutamente defensivas, visando promover investimentos e /ou proteger empregos do setor automobilístico, praticando formas variadas de renúncia tributária, acabaram contribuindo para implantar mais e mais o caos urbano e a péssima qualidade do transporte público, além de fragilizar os governos locais e favorecer seu aprisionamento pelos grandes interesses econômicos.

Para recuperar a capacidade de planejamento e de pensar as urbes que desejamos no futuro é preciso conectar analiticamente três eixos de questões ou problemas: o papel da indústria automobilística no processo de desenvolvimento, a dinâmica do capital imobiliário e a (in)segurança pública. Ao mesmo tempo, esta reflexão envolve a capacidade política dos governos municipais de enfrentar essas questões, e não menos importante, admitindo a sua fragilidade financeira, que tipo de arranjo federativo horizontal e/ ou vertical será necessário para recuperar a capacidade de intervenção. Entre as carências das metrópoles brasileiras, muitos autores apontam que, na federação brasileira,

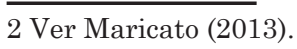


inexistem instâncias públicas metropolitanas, dotadas de mandatos e fundos públicos, especificamente criados para atuar de modo permanente nessas áreas que, ainda, possuem dimensões jurídicas e constitucionais difusas. Apesar das suas limitações ou dos seus "brancos" o Estatuto da Metrópole (ainda em tramitação) constitui um bom ponto de partida para inserirmos esta discussão no espaço metropolitano e, não menos importante, socializar a idéia de que a cidade é a metrópole que aglutina inúmeros municípios heterogêneos. ${ }^{3}$ Evidentemente que os aglomerados metropolitanos, que estão na vanguarda dos problemas urbanos, abrigando imensos contingentes populacionais, longe estão de exaurir o universo das cidades brasileiras.

De certa maneira, a revisão do papel estratégico desses eixos conduz a um questionamento do modelo de crescimento praticado no País e seu sucesso e/ ou fracasso em implantar uma via de desenvolvimento fordista e americanizada. Aposta-se na venda de automóveis para todo mundo e aplaude-se um boom imobiliário. Defendem-se cadeias produtivas generosas na geração de empregos, mas não se questionam as bases de seu funcionamento nem as conseqüências nefastas da proliferação de seus produtos. A defesa incondicional e passiva destes vetores do crescimento pode acabar bloqueando de modo definitivo a possibilidade de construir espaços urbanos civilizados, condenando as próximas gerações a viver em clima de permanente opressão.

A massificação perversa do automóvel (e o encurtamento do seu ciclo de vida), num país sem transporte público de qualidade, estreita o raio de manobra das políticas urbanas que visam propiciar condições de mobilidade. Pior ainda, estimula a hiper atividade da cidade, a circulação veloz e inútil dos indivíduos, o deslocamento sem sentido e apaga a identidade que só a pausa e a serenidade podem gerar. A cidade não produz o desejo de ficar, de estar, transforma-se literalmente numa roda viva.

Por sua vez, o capital imobiliário avança sem restrições, ocupa sistematicamente, do centro à periferia, os melhores terrenos, verticalizando e horizontalizando comunidades condominiais. Joga cada vez mais longe dos centros empregadores a população trabalhadora, condenados a viver em guetos degradados, em residências minúsculas, pois em qualquer lugar, os terrenos são monopolizados por grandes incorporadores que apenas ajustam as escalas do poder de compra. Constroem praticando margens de lucro acima de cem por cento. Num país com um padrão salarial baixo, marcado por elevadíssima concentração de renda, a habitação também se massifica de modo perverso, reproduzindo fraturas sociais históricas. O grande programa de habitação do governo "Minha Casa, Minha Vida", com alcance popular importante (olhando retrospectivamente), condena os pobres deste país continental (onde a terra nunca foi de livre acesso ou "abundante") a viver em cubículos que se assemelham ao padrão habitacional de Tokyo, onde indivíduos com elevadíssimo nível de vida vivem em poucos metros quadrados.

Para completar a tríade proposta, a totalidade do espaço urbano é democraticamente vitimado pela violência, roubos e assaltos, alimentados pela cultu-

3 Ver Moura e Carvalho (2012) e Moura e Firkowski (2005) 
ra materialista do consumo, pelo ressentimento e a desilusão. Afinal de contas, neste ambiente social, uma vida é demasiado curta para se conseguir consumir tudo o que os de cima tem por mérito ou não. O medo leva as famílias a desejar habitar em condomínios verticais ou horizontais fechados, repletos de câmeras e pessoal de seguridade. A indústria da segurança cresce ao ritmo da cidade, privatiza e fragmenta a cidade e, para completar a obra irracional, impõe aos governos pautas cada vez mais conservadoras. Esta gigantesca cadeia produtiva, junto aos outros dois eixos, transforma a cidade num espaço a ser sofrido e vivido de modo cada vez mais parcial e angustiante. Não é possível, sem intervir nestes eixos, pensar o que será das cidades brasileiras no futuro.

No caso dos automóveis e do capital imobiliário, trata-se de fortalecer o poder regulador do Estado e a regulação estabelecerá limites que, a curto prazo, poderão parecer exagerados ou "anti mercado" mas, a longo prazo serão plenamente justificados.

Para recuperar a capacidade de intervenção, especialmente dos governos locais, é importante entender a urgência de reconsiderar as bases de sustentação do seu financiamento, o que leva a melhorar seus dois impostos próprios: IPTU e ISS. Fazendo analogia com o princípio do "poluidor-pagador", são justamente esses dois eixos, a indústria automobilística e o capital imobiliário, que deveriam constituir as áreas econômicas em condições de fortalecer as bases fiscais dos governos. É um paradoxo que essas cadeias produtivas ricas convivam com prefeituras pobres e imobilizadas. De certa forma, estas opções constituem dilemas para os governantes submetidos ao ciclo político, é muito provável que algum capital eleitoral seja queimado ao tomar certas decisões, talvez suficiente para inviabilizar a continuidade deles. Observe-se que, níveis superiores de governo mais próximos à gestão macroeconômica poderão argumentar contra medidas que afetem negativamente decisões das montadoras ou freiem investimentos imobiliários. Por isso é crucial construir apoios a partir de novas (velhas) questões que apontem para a construção urbana que desejamos e o "direito à cidade".

As cadeias produtivas da violência e da segurança constituem engrenagens muito mais complexas e multi determinadas. Seus nexos causais ligados a fatores históricos e exacerbados pela cultura do consumismo e do individualismo, só poderão ser desarticulados se o Estado recuperar sua capacidade de planejamento e intervenção e, se os governos locais conseguirem investir em espaços e equipamentos públicos de qualidade capazes de revalorizar a cidade e, desta forma, fazer que a sociedade passe a defendê-la com a intensidade e paixão de quem se sente responsável pela sua construção. Antes de mais nada será necessário recuperar o gosto de andar ou pedalar, de ficar na cidade, em vez de circular por motivos apenas utilitários. Isto remete ao tempo livre que poderá ser liberado a partir destas intervenções e às políticas de lazer e cultura que são tão estruturantes quanto as políticas de saúde e de transportes.

Sem atacar de modo global, profundo e abrangente, as questões derivadas destes eixos, debatendo e produzindo entendimentos e, quem sabe, retomando na agenda pública o tema da reforma urbana, de nada servirá pensar em 
"cidades do conhecimento" ou "cidades limpas".

\section{Réplica}

Para que o leitor tenha condições de partilhar as preocupações com o futuro das nossas cidades, o texto deveria ser mais longo e trabalhado. Por exemplo, poderia ser enfatizado o grande papel do município nos gastos com saúde e educação, além de transporte público, o que deve limitar sua atuação em outras áreas também cruciais. Em torno da questão das finanças federativas há uma luta política pelo excedente social. Se os municípios, por exemplo, tivessem mais recursos, como se reordenaria a ação política e econômica dos grandes bancos e das grandes firmas industriais como a automobilística? Como construir um espaço democrático de contestação a estes se atuam em nível mundial com a indústria petroleira, o mundo globalizado das finanças, interesses americanos e indústria armamentista? O Estado nacional é frágil diante dessas questões, o que coloca difíceis problemas à sua democratização e soberania. Penso sobretudo no Brasil, onde esses interesses externos não tem contraposição de setores que nunca existiram, como o grande empresário nacional.

Por outro lado, mesmo o Banco do Brasil e a Caixa Econômica sancionam com seu crédito imobiliário a lógica e o desenho do espaço urbano. Ao mesmo tempo, a mídia, os bancos privados, o legislativo clientelista, ajudam a limitar o Estado. Aproveitaram as manifestações, que aparentemente se diluiriam, por exemplo, na construção problemática da Rede Sustentabilidade e da candidatura em 2014 de Marina Silva. É no mínimo estranho que estas tenham sido alvo de apoio da mídia e outros atores de grande peso, quando estes deixaram de destacar da mesma forma manifestações sindicais que ocorreram concomitantemente, bem como a greve dos correios, dos bancários e dos professores estaduais, que foram duramente reprimidos no Rio. Parece que a população pode reclamar por maiores gastos com saúde e educação, ou contra a corrupção de políticos, mas quando setores organizados ligados ao mundo do trabalho fazem suas demandas publicamente, não interessam ao conservadorismo político e midiático, talvez porque caracterizem uma comemorada extinção da luta de classe. Pode-se perguntar o que significaria a candidatura desejada de Marina Silva nesse contexto. Mas outras manifestações mais gerais têm ocorrido, sem espaço na mídia, o que mostra o desejo de contê-las e instrumentalizá-las.

Mas as manifestações inicialmente enfatizaram a corrupção dos políticos, pedindo, por exemplo, prisão para os réus do mensalão. Falaram o que se ouve da mídia e nas declarações reiteradas sobre este último, mas não levantaram o problema de como pensar a corrupção que há nos negócios privados, na simbiose público/privado destes últimos. Tampouco mencionaram, no jogo de cena do STF, seu caráter eleitoral, ou a forma como a corrupção entra nas licitações públicas, na gerencia de hospitais públicos, que estão sendo privatizados junto com parte da previdência social e amanhã talvez da universidade pública. Como entender o tráfico sem estes interesses? A partir do mano que dorme na rua? Muitas vezes ele dorme na rua, mas levanta cedo, descarrega frutas 
no Ceasa, e assim por diante. É importante que os protestos aprofundem sua percepção do que ocorre, o que depende de como eles são organizados, em uma sociedade tão pouco transparente como a nossa.

A insegurança urbana, para nos restringirmos à violência e criminalidade, tem uma componente estrutural na desigualdade bem como na apartação urbana. São problemas históricos, que se referem ao maltrato e descaso do Estado para com o conjunto da sociedade. Esta é uma sociedade maltratada e vítima de uma ineficaz disciplinarização, pelo sistema político e pelo elitismo dos muito ricos, contra os quais o estado nunca pôde muito, e que são os responsáveis em última análise pela corrupção, o tráfico, e pela falta de planejamento das cidades e metrópoles. É um problema também que passa pela violência policial. Houve várias tentativas de controle da polícia militar que não tiveram sucesso. A violência policial tem a ver com a militarização da polícia, sua ética de subordinação violenta dos mais graduados sobre soldados, que a reproduzem sobre os que são alvo de qualquer incidente que possa ser considerado, mesmo arbitrariamente, um problema para ser resolvido pela polícia. No Rio de Janeiro há um uso gritante da polícia contra moradores de comunidades mais carentes e sua cultura, bem como contra manifestações como a de professores estaduais denunciando sua precária condição de trabalho.

A insegurança tem a ver também com a suspeita que ronda os pobres. Os shoppings reforçam seu efetivo de segurança aos domingos, quando os pobres vão tomar sorvete aos pares amorosos e ver as vitrines, por exemplo. Os próprios shoppings são lugares onde o principal produto é a segurança e apartação. Um shopping como o Novo Batel em Curitiba é quase blindado, sem janelas, num bairro onde o padrão dos edifícios, ou o calçamento, são nitidamente diversos de outros bairros menos opulentos ou do centro deteriorado da cidade.

Fazendo um recuo, é bastante conhecido que a classe média criada com o milagre deteriorou-se com o desmonte do estado e as novas formas de organização da grande empresa industrial e bancária, entre outros, atingindo também uma elite operária e seus sindicatos. A nova classe trabalhadora, identificada publicitariamente como classe média nova, levou ao mercado de trabalho formal contingentes de desempregados e trabalhadores informais. O desemprego baixou, a desigualdade de renda melhorou, mas os muito ricos criados nos anos noventa mantiveram sua força sobre o Estado nas questões relevantes como o nível da taxa de juros, o padrão salarial, os recursos para políticas sociais e outros. O desempenho econômico manteve crescimento baixo do PIB no ritmo lento de novos investimentos, prevalecendo os interesses do predador agrobusiness e da mineração. Só não foi pior porque há bons compradores no mercado internacional que mantém ritmo de crescimento elevado graças a uma maciça intervenção estatal, como a notória China. Mas também essa nova classe trabalhadora beneficiou-se de possibilidade de endividamento, maiores níveis dos salários de base e outros elementos, o que manteve expansão dos serviços e da automobilística, bem como os negócios das construtoras, com mercado em expansão diante da nossa desenfreada metropolização.

Não houve uma nova lógica de consumo, nem uma ética diversa nascida 
nos novos insiders. Esta vai aparecer de súbito nas demandas das manifestações, exigindo protagonismo político e cidadania, mas monitorada, tanto quanto possível, pela mídia e sistema político. O Estado pode atender algumas dessas demandas, mas de modo incerto a meu ver. Por exemplo, pode trazer médicos cubanos, que a população dos pequenos centros urbanos vê com alegria, mas esta é uma ação emergencial. Pode construir como vem fazendo novas universidades e escolas técnicas, mas não pode zelar para que nelas não prevaleça uma lógica particularista, um ensino convencional ligado a uma ótica produtivista. Como garantir desenvolvimento e ascensão social em um quadro de salários baixos e redefinidas demandas populares, genéricas ou mais especificamente trabalhistas? Elementos que suportariam a industrialização e a mobilidade são freados pelo baixo investimento público, a elevada taxa de juros, o cambio preso na dança das oscilações do mercado financeiro mundial.

Para concluir, o texto aponta bem aspectos centrais na questão urbana, destacando três que julgou mais relevantes para reflexão. Estes três eixos, girando em torno do novo precário padrão de civilização, muito bem identificados, sobretudo porque envolvem o inesgotável problema do papel que o automóvel assumiu no Brasil em detrimento do transporte público, e ao mesmo tempo como signo visível de "sucesso" na vida privada, desligada de uma solidariedade social. Mas ele se apressa em dar soluções, o que não precisava fazer, bastando apontar os problemas, como fez muito bem. O texto joga ademais essas soluções para o Estado, frágil em termos políticos e econômicos e sem grande sensibilidade para o social. Talvez seja melhor pensar a cidade ou a metrópole como o corpo mutável de lutas sociais, a vivência de lutas de classe que não se resolvem, benignamente, por sua atribuição ao Estado, mas que se desenvolvem chamando nossa participação. As manifestações foram um momento privilegiado dessas lutas, inclusive por certa ambiguidade dada a disputa política em torno de seu significado.

\section{Conclusão}

As demandas expressas nas manifestações de junho trazem à tona um conjunto problemas que assolam as nossas metrópoles há tempos. Em primeiro lugar, o transporte público caro e de má qualidade, num contexto que privilegia o uso das vias pelo transporte individual, mais poluidor e grande responsável pelas dificuldades de mobilidade urbana. Não basta reduzir preços de passagens, é preciso repensar o uso do automóvel como meio de transporte principal na cidade. É um grande desafio para os gestores municipais, tendo em vista que toda mudança significa confronto com interesses econômicos, todavia, a qualidade de vida na cidade pede uma ação efetiva neste sentido.

Em segundo lugar, a cidade apresenta-se cada vez mais como um espaço desigual e extremamente excludente, quando se trata do modelo de habitação. Mesmo com a evolução recente nos níveis salariais no Brasil, os trabalhadores estão cada vez mais apartados do centro da cidade, se refugiando nas periferias 
distantes, que carecem de infraestrutura básica e de acesso a serviços como saúde e educação.

É certo que a própria dinâmica econômica baseada em incentivos ao consumo contribui para estes problemas. Se de um lado o setor automobilístico tem sido pilar importante deste modelo de crescimento baseado no consumo; o crédito também farto para a compra da casa própria impulsiona o setor imobiliário com a construção de moradias ínfimas financiadas em prazos longos, endividando as famílias pobres e confinando-as em bairros afastados, nos quais a presença do poder público pouco se faz sentir.

O terceiro ponto é a insegurança urbana que assombra a vida de todos os moradores da cidade e cada vez mais atinge os diferentes recantos da metrópole. Discutir segurança pública é mergulhar num tema controverso e, mais do que tudo, com múltiplas determinações. Há componentes de desigualdade, exclusão e fraturas sociais, que se expressam na indiferença, no isolamento e na violência. Há também o tráfico de drogas que é o combustível que incendeia a periferia e é o caminho mais fácil de ascensão social para muitos jovens sem perspectivas. A violência não está conectada apenas com pobreza, desemprego ou mesmo com falta de efetivos policiais, como muitos argumentam. É resultado da indiferença e do abandono de determinados grupos sociais. Populações segregadas e excluídas que carecem do sentimento de pertencimento social.

Trata-se, portanto, de um ambiente social fragmentado; individualista; em que o consumo é símbolo de status e felicidade; com cidadãos indiferentes às dívidas sociais e com uma inércia social e política marcantes.

É este contexto da cidade que produz este mal-estar social. Falta de serviços de qualidade de um lado, mas também uma vida comunitária que precisa ser resgatada em nome de uma nova cidade, de um novo espaço urbano digno de se viver e conviver.

\section{Referências}

Harvey, David (2013) A liberdade da cidade. In: Cidades rebeldes: passe livre e as manifestações que tomaram as ruas do Brasil. Textos encomendados. Primeira Edição. São Paulo: Editora Boitempo: Carta Maior.

Maricato, Ermínia (2013) É a questão urbana, estúpido! In: Cidades rebeldes: passe livre e as manifestações que tomaram as ruas do Brasil. Textos encomendados. Primeira Edição. São Paulo: Editora Boitempo: Carta Maior.

Moura, Rosa E Carvalho, Ilce. (2012) Estatuto da Metrópole: onde esta a região metropolitana? Boletim do INCT, Rio de Janeiro, n. 266.

Moura, Rosa E Firkowski, Olga. (2005) Estatuto Da Metrópole. Contribuição Ao debate. Observatório das Metrópoles, Rio de Janeiro. 
